\title{
ChemComm
}

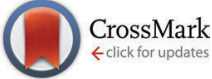

Cite this: Chem. Commun., 2016, 52,6257

Received 22nd February 2016, Accepted 6th April 2016

DOI: $10.1039 / c 6 c c 01606 e$

www.rsc.org/chemcomm

\section{Intense chirality induction in nitrile solvents by a helquat dye monitored by near resonance Raman scattering $\dagger$}

\author{
Jaroslav Šebestík, ${ }^{\star a}$ Filip Teplý, ${ }^{* a}$ Ivana Císařová, ${ }^{b}$ Jan Vávra, ${ }^{a}$ Dušan Koval ${ }^{a}$ and \\ Petr Bouřta
}

Chirality induction phenomena attract attention because of their relevance to intermolecular interactions encountered in living matter. Usually, such effects are weak. However, enantiomers of a [6]helquat dye were found to induce exceptionally strong chirality in several achiral solvents containing nitrile groups. This effect was observable as an intense Raman optical activity (ROA) induced in acetonitrile, acetonitrile- $d_{3}$, and liquid hydrogen cyanide solvents. The observation was verified by measurement of both helquat enantiomers which provided mirror image ROA spectra. Theoretical analysis indicated that the $532 \mathrm{~nm}$ laser excitation light was in a near resonance with electronic transitions of the dye, which made the effect observable in very dilute solutions (1:200000 helquat to nitrile ratio) and thus the phenomenon can be generally useful in analytical chemistry.

Chirality, the left- and right-hand symmetry, is an inherent property of life on the Earth. Because of this, chiroptical phenomena, such as optical rotation and optical rotatory dispersion, have attracted attention since the pioneering work of Louis Pasteur. ${ }^{1}$ The electronic ${ }^{2}$ and vibrational ${ }^{3}$ circular dichroism (ECD, VCD), and more recently vibrational Raman optical activity (ROA) ${ }^{4}$ have also been established as standard chiroptical techniques which provide unique information on the molecular structure.

Chiral stereospecific molecular interactions are also necessary for the functioning of living cells. Chirality transfer from chiral molecules resulting in induction of optical activity in otherwise achiral solvents can thus lead to a valuable insight into intermolecular interactions including the structure of solvation spheres. Chirality transfer was observed for numerous systems including DNA and acridine orange ${ }^{5}$ proteins interacting with quinolines and acridines, ${ }^{6}$ and polysaccharides with acridine

\footnotetext{
${ }^{a}$ Institute of Organic Chemistry and Biochemistry, Academy of Sciences of the Czech Republic, v.v.i., Flemingovo n. 2, 16610 Prague 6, Czech Republic.

E-mail: sebestik@uochb.cas.cz, teply@uochb.cas.cz,bour@uochb.cas.cz

${ }^{b}$ Department of Inorganic Chemistry, Charles University, Hlavova 2030/8,

12843 Prague 2, Czech Republic

$\dagger$ Electronic supplementary information (ESI) available. CCDC 925832 and 925833. For ESI and crystallographic data in CIF or other electronic format see DOI: $10.1039 / \mathrm{c} 6 \mathrm{cc} 01606 \mathrm{e}$
}

ligands. ${ }^{7}$ Usually, a stable and tight complex between the chiral and achiral parts must be formed for the effect to be detectable.

Only a few cases of weakly interacting solvents and solutes have been described in this context. For example, a camphorinduced VCD signal attributed to the C-D stretching in the $\mathrm{CDCl}_{3}$ solvent has been reported. ${ }^{8}$ Similarly, some features in optical rotatory dispersion spectra of $(S)$-methyloxirane in benzene were explained by a significantly chiral arrangement of the solvation sphere. ${ }^{9}$

The [6]helquat dye (HQ) enantiomers (Scheme 1) presented here induce exceptionally large Raman optical activity (ROA) in nitrile solvents. This surprising effect is partially attributed to the enhancement of Raman scattering, due to a near resonance between the green $532 \mathrm{~nm}$ excitation laser light and $\mathrm{S}_{0} \rightarrow \mathrm{S}_{1}$ electronic transition of the helquat dye. The ROA signal can be detected for concentrations as low as $3 \times 10^{-5} \mathrm{M}$. To the best of our knowledge, this chirality transfer phenomenon has not been described before.

The [6] helquat and similar helical cations have been investigated as versatile compounds used in organic chemistry and materials science. ${ }^{10-12}$ Similar to non-polar helicenes, they exhibit a strong chiroptical signal and robust chemical stereoselectivity. Moreover, helquats are easy to prepare and can

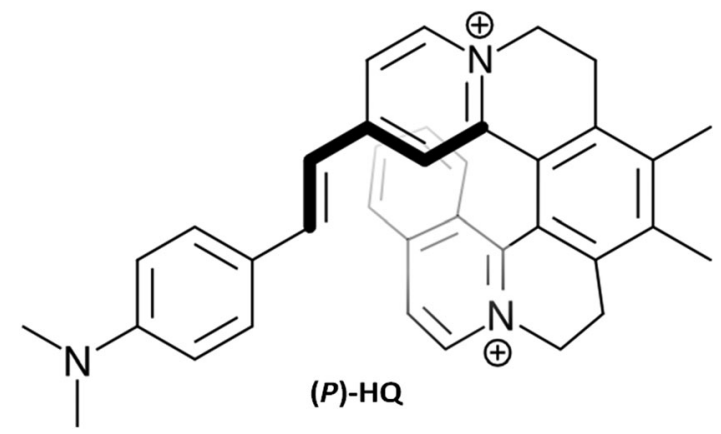

Scheme 1 The [6] helquat dye (enantiomer of $P$ helicity) investigated in the present study; accompanying trifluoromethanesulfonyl anions are not shown. 
strongly interact with the environment due to their charged polar parts.

ROA spectroscopy itself is a relatively new and dynamically evolving technique. It measures a tiny difference in scattering of the right- and left-circularly polarized light. The possibility of using water as a solvent (which is problematic for infrared vibrational techniques) and its flexible experimental setup make this technique especially advantageous for biomolecular studies. ${ }^{13}$ The ratio of the ROA difference to the total Raman intensity (circular intensity difference, CID) is rather small for organic molecules, typically of the $10^{-4}$ order. In the past, several strategies to increase the signal were explored including surface enhanced scattering, ${ }^{14}$ induced resonance ${ }^{15}$ and inherent resonance. ${ }^{16}$ In this context, the chirality transfer has interesting and underexplored potential for increasing the sensitivity of ROA measurements.

At the outset of this study, we tested some helquats in near resonance with the $532 \mathrm{~nm}$ laser excitation as agents for Raman signal enhancements. Their Raman spectra can be easily measured at a concentration of $0.07 \mathrm{mg} \mathrm{mL}^{-1}$ : their bands are almost as intense as that of the used solvent ( $c f$. Fig. S1 and S2 for the [6]helquat dye HQ in the ESI $\dagger$ ).

Surprisingly, ROA spectra showed a large and unanticipated induction of ROA bands in the nitrile solvents used. For the [6] helquat (HQ) enantiomers dissolved in three nitrile solvents the ROA spectra are plotted as in Fig. 1. Clearly, the nitrile bands of the achiral solvent dominate the spectra; ROA of the HQ itself (primarily between 1000 and $1600 \mathrm{~cm}^{-1}$ ) is relatively weak and obscured by fluorescence. A possibility of experimental artifacts was excluded by measuring both HQ enantiomers, which provided nearly mirror image ROA spectra, well above the noise level (control ROA spectra of racemic HQ solutions can be seen in Fig. S3-S5, ESI †). The peak frequencies of solvent vibrations in neat solvents and HQ solutions are nearly the same (Table S1, ESI $\dagger$ ) which indicates that the underlying process

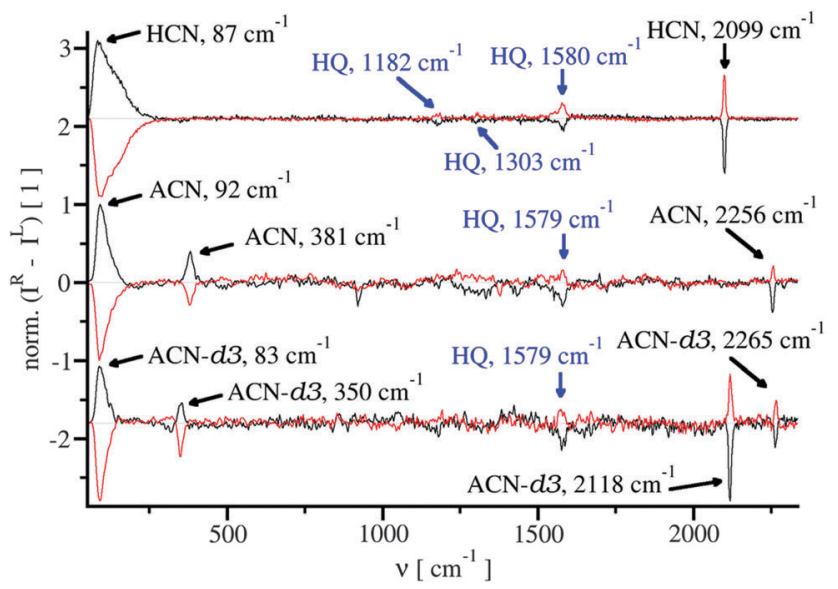

Fig. 1 Experimental ROA spectra of [6] helquat dye $\left(H Q\right.$, in $9 \times 10^{-5} M$ concentration) solutions in three nitrile solvents $\mathrm{HCN}$, acetonitrile $(\mathrm{ACN})$, and acetonitrile- $d_{3}\left(A C N-d_{3}\right)$. Black and red curves correspond to solutions of the $(P)$ - and $(M)-H Q$ enantiomers, respectively. The strongest ROA peaks of $\mathrm{HQ}$ and each solvent are indicated by arrows. The typical acquisition time was 24 hours (see also the ESI $\dagger$ ). is "ordinary" Raman scattering (and not circularly polarized luminescence, for example). ${ }^{17}$ Experimental data also do not indicate unusual HQ-solvent interactions, such as covalent bond formation or involvement of ion pairing. On the other hand, addition of methanol destroyed the induced ROA signal, which implies that some short-distance solvent-solute interaction is necessary for the effect.

A closer look at the spectra (Fig. 1) reveals that ROA bands at $87 \mathrm{~cm}^{-1}$ for HCN, 92 and $381 \mathrm{~cm}^{-1}$ for ACN, and 83 and $350 \mathrm{~cm}^{-1}$ for ACN- $\mathrm{d}_{3}$ have opposite signs as compared to the bands above $1000 \mathrm{~cm}^{-1}$, i.e. $2099 \mathrm{~cm}^{-1}$ for $\mathrm{HCN}, 2256 \mathrm{~cm}^{-1}$ for ACN, and 2118 and $2265 \mathrm{~cm}^{-1}$ for ACN-d $\mathrm{d}_{3}$. Since a single-state ROA resonance theory ${ }^{18}$ would be consistent with a one-sign ROA pattern only, our experiments suggest that multiple excited states or multiple $\mathrm{HQ}$ conformers $^{19}$ or $\mathrm{HQ}-\mathrm{ACN}$ cluster geometries (Table S3, ESI $\dagger$ ) are involved. On the other hand, the ROA signal of the HQ dye is nearly of one-sign only, which is expected as the sign is dictated by the rotational strength of the resonating electronic transition. ${ }^{13}$

Acetone and propionitrile were also tested as solvents (Fig. S6, ESI $\dagger$ ); however, no ROA signal could be measured because of high HQ fluorescence. In the series of nitriles, fluorescence of HQ increases with increasing hydrophobicity and size (HCN < ACN < propionitrile). Induced ROA can be still observed in a mixture of propionitrile and ACN (1:3, Fig. S9, ESI $\dagger)$ and a mixture of methanol and ACN (1:7, not shown), but quickly disappears for higher co-solvent: ACN ratios.

To understand the phenomenon we have carried out several density functional theory (DFT) calculations. According to them, HQ can exist in two conformers differing by the conformation of the ethylene linkage (Fig. 2A and B, Table S2, ESI $\dagger$ ), although only the s-cis conformer (Fig. 2A and Scheme 1) was found by X-ray crystallography. Several HQ-ACN ad hoc complexes were constructed, to investigate preferential binding modes.

The calculations indicate that even individual HQ conformers are partially flexible and the interaction with ACN molecules leads to HQ deformations due to the polar interactions and van der Waals attraction of the aromatic moieties. These changes in HQ geometry as well as the structural variations of the solvation sphere can flip ROA band signs of the nitrile solvent vibrations including CN stretching.

Due to computer limitations, clusters of HQ with the solvent comprising the whole first hydration sphere could be treated with a small STO-3G basis set only. This is not sufficient for quantitative modeling, nevertheless such computations showed that Raman and ROA intensities coming from individual ACN molecules were dramatically influenced by the interaction with HQ. In a randomly selected cluster, for example, two out of $41 \mathrm{ACN}$ molecules were responsible for $50 \%$ of the total nitrile Raman scattering intensity (Fig. 2C), as well as, for $50 \%$ of the total nitrile ROA intensity (Table S3, ESI, $\dagger$ cluster $\mathrm{j}$ ). In addition, both the intensity and sign of induced ROA are dependent on details of the cluster geometry (Table S3, ESI†).

Molecular dynamics (MD) simulations were conducted to explore the HQ solvation sphere in detail. The triflate anion $\left(\mathrm{CF}_{3} \mathrm{SO}_{3}{ }^{-}\right)$was approximated by $\mathrm{Cl}^{-}$. These simulations have shown that HQ-ACN interactions lead to a well-ordered structure 


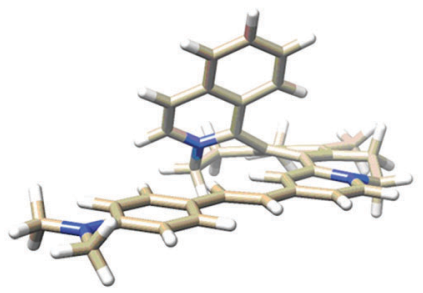

A

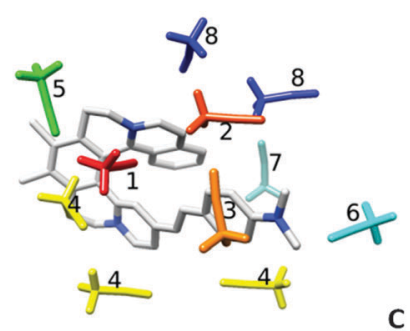

C

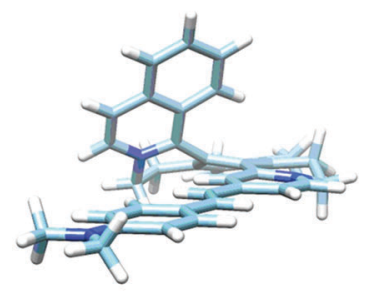

B

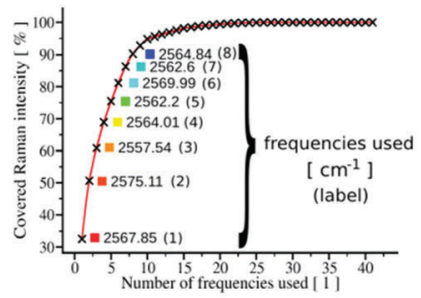

Fig. 2 (A): $(P)-\mathrm{HQ}$ with s-cis conformation of the ethylene linkage (see also Scheme 1 for structural formula); $(B):(P)-H Q$ with s-trans conformation of the ethylene linkage (see Table S2, ESI + ); (C): total Raman intensity of a $\mathrm{HQ}(\mathrm{ACN})_{41}$ cluster plotted against the number of vibrations taken in the summation. Vibrations of the most contributing $\mathrm{ACN}$ molecules (left) are marked by the same color and labeled as in the graph on the right. Cluster properties are calculated at the BPW91/STO-3G level with the s-cis conformer.

of the first solvation sphere (Fig. 3), where ACN molecules are obviously organized in a chiral fashion. From the MD snapshots, $\mathrm{HQ} / \mathrm{ACN} / \mathrm{Cl}^{-}$clusters were constructed by removing ACN molecules and $\mathrm{Cl}^{-}$ions outside the first solvation sphere. After partial optimization in vibrational normal mode coordinates ${ }^{20}$ ROA spectra were calculated using the Cartesian coordinate tensor transfer (CCT) method. ${ }^{21}$ Note that CCT makes ROA spectra for individual components of the cluster, i.e. HQ and ACN. It does not account for their strong interaction (other than electromagnetic) and for the very different Raman signal of individual ACN molecules in the vicinity of HQ that was indicated by the DFT computations above. Nevertheless, this model confirmed again the possibility of chirality induction although on a qualitative level (Fig. S7, ESI $\dagger$ ). As expected, the near resonance one-sign HQ ROA signal is conserved even in the presence of the solvent (Fig. S7, ESI $\dagger$ ).

As the last approximation, the empirical transition polarizability model $(\mathrm{TPM})^{22}$ where the solute and solvent are

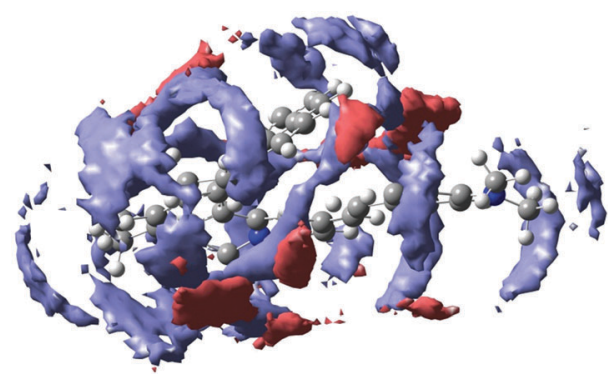

Fig. 3 Average densities of ACN carbon (red) and nitrogen (blue) in the $(P)-\mathrm{HQ}$ solvation sphere obtained from 5 ns MD simulation.

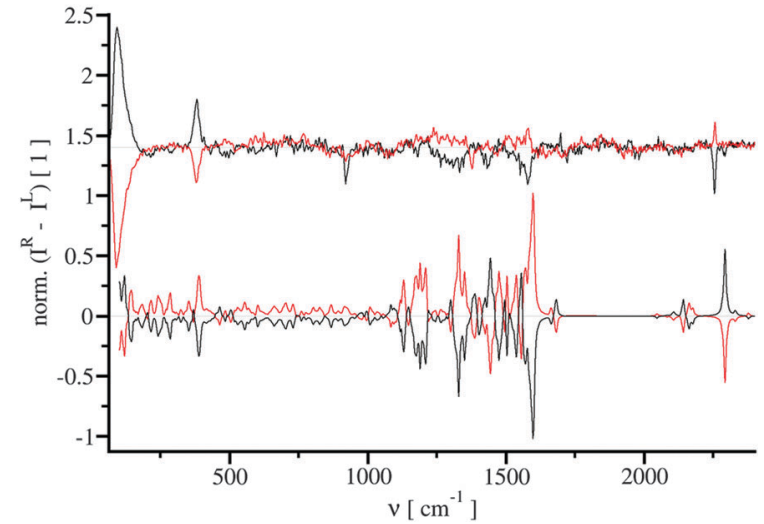

Fig. 4 Experimental (top) and calculated (bottom) ROA spectra of $H Q$ in ACN. For the calculation, the TPM model and 1000 MD averaged clusters were used. Black curves correspond to $(P)-\mathrm{HQ}$ and red curves to $(M)-\mathrm{HQ}$.

represented only by polarizable particles (Fig. S8, ESI †) was used. This approach can be thought of as a simpler variant of the CCT method from the previous paragraph and allows one to estimate the convergence of spectral intensities while averaging a large number of MD clusters. The TPM spectra (Fig. 4) qualitatively reproduce the induced solvent chirality, comparable to that of the solute. TPM also confirms that solvent orientation in the first solvation sphere is most important for the induced chiral response. However, a relatively large number of MD clusters $(>400)$ need to be averaged (Fig. 5). At present, this cannot be achieved at a higher $a b$ initio level using available computational resources.

Nevertheless, the computational modeling provides useful insights into the phenomenon. For ACN, the proposed chirality transfer scheme is presented in Fig. 6. The $532 \mathrm{~nm}$ excitation laser light is in a (near) resonance with the $\mathrm{S}_{0} \rightarrow \mathrm{S}_{1}$ HQ electronic transition. Most of the absorbed energy is emitted as fluorescence, with a relatively weak Raman component. Acetonitrile and similar solvents do not exhibit fluorescence, but their Raman scattering becomes more intense in the vicinity of the HQ dye,

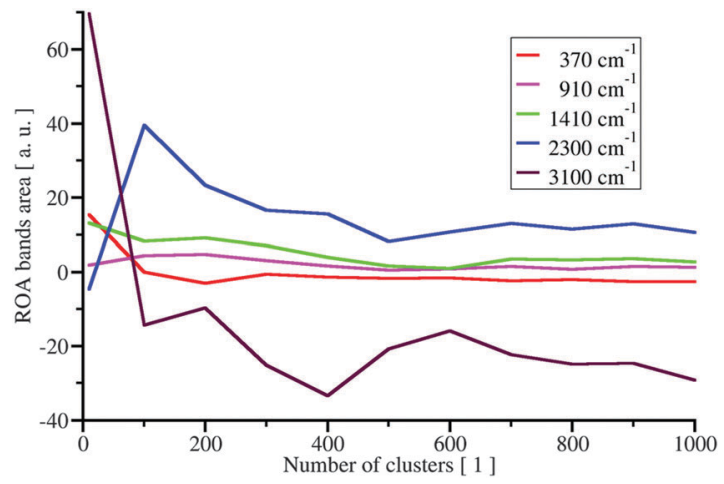

Fig. 5 Intensities of selected simulated ACN ROA peaks dependent on the number of clusters taken into averaging within the TPM approach (peaks at different wavenumbers in $\mathrm{cm}^{-1}$ are indicated by color code). For example, in the case of the $\mathrm{CN}$ band at $2300 \mathrm{~cm}^{-1}$ (blue), the intensity remains essentially constant when more than 400 clusters are averaged. In our TPM model, 1000 clusters were used for simulation of spectra. 


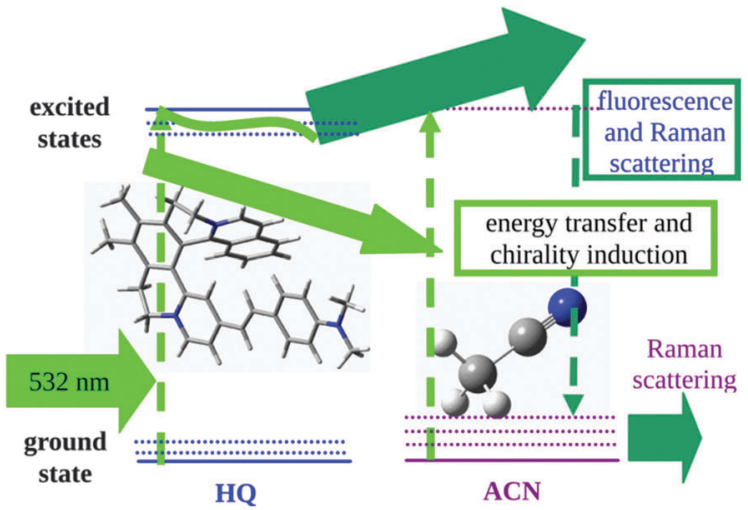

Fig. 6 Proposed mechanism of the chirality transfer.

due to an "antenna" effect, i.e. transfer of energy from the dye. The ACN molecule itself does not absorb the $532 \mathrm{~nm}$ laser light, but as molecular orbital analysis (Fig. S10, ESI $\dagger$ ) suggests the HQ cation can share an electronic space with a close ACN molecule; thus the energy and chirality transfers are possible. The most strongly scattering ACN molecules ( $c f$. Fig. 2C) lie in the first solvation sphere of $\mathrm{HQ}$, which is significantly structured ( $c f$. Fig. 3) and provides a strong ROA signal.

In summary, we have observed a large ROA signal of the nitrile solvents induced by an enantiopure [6] helquat dye. This serendipitously discovered phenomenon indicates a new mechanism of the chirality transfer. We explained this effect by a resonance of the helquat molecule with the incident laser beam and associated Raman intensity enhancement in close-lying solvent molecules. The chirality is thus imprinted in the structure of the first solvation sphere of a helquat dye as was also confirmed by the molecular dynamics simulations. This new effect has an extraordinarily large magnitude and is observable already at a 1:200 000 solute: solvent ratio. This phenomenon has the potential to be developed into a useful tool to probe molecular chirality and intermolecular interactions for structural chemistry and biology. Although we were able to reproduce principal features in the observed spectra on the basis of the cluster and TPM models, better quantitative interpretation remains a challenge for theoretical chemistry. It is clear that the phenomenon is quite complex involving resonance, energy transfer, and molecular dynamics phenomena.

This work was supported by the Czech Science Foundation (14-00431S, 16-05935S, 15-09072S, 13-19213S, and 13-32974S), Academy of Sciences (M200551208), RVO research project (61388963), and MetaCentrum computational resources (LM2010005 and
CZ.1.05/3.2.00/08.0144). We thank Mr M. Jirásek for growing $\mathrm{X}$-ray quality crystals.

\section{Notes and references}

1 L. Pasteur, Theses de chimie et de physique, Bachelier, Paris, 1847.

2 R. W. Woody, Adv. Biophys. Chem., 1992, 2, 37.

3 G. Holzwarth, E. C. Hsu, H. S. Mosher, T. R. Faulkner and A. Moscowitz, J. Am. Chem. Soc., 1974, 96, 251.

4 L. D. Barron, M. P. Bogaard and A. D. Buckingham, J. Am. Chem. Soc., 1973, 95, 603; D. Barron, Nature, 1975, 255, 458; J. Haesler, I. Schindelholz, E. Riguet, C. G. Bochet and W. Hug, Nature, 2007, 446, 526.

5 M. Zama and S. Ichimura, Biopolymers, 1970, 9, 53.

6 F. Zsilla, J. Visy, G. Mády and I. Fitos, Bioorg. Med. Chem., 2008, 16, 3759.

7 F. Zsilla and G. Gedeon, Biochem. Biophys. Res. Commun., 2006, 346, 1267.

8 E. Debie, L. Jaspers, P. Bultinck, W. Herrebout and B. van der Veken, Chem. Phys. Lett., 2008, 450, 426.

9 P. Mukhopadhyay, G. Zuber, P. Wipf and D. N. Beratan, Angew. Chem., Int. Ed., 2007, 46, 6450; J. Neugebauer, Angew. Chem., Int. Ed., 2007, 46, 7738.

10 Initial report on helquats: L. Adriaenssens, L. Severa, T. Šálová, I. Císařová, R. Pohl, D. Šaman, S. V. Rocha, N. S. Finney, L. Pospíšil, P. Slavíček and F. Teplý, Chem. - Eur. J., 2009, 15, 1072.

11 L. Pospíšil, L. Bednárová, P. Štěpánek, P. Slavíček, J. Vávra, M. Hromadová, H. Dlouhá, J. Tarábek and F. Teplý, J. Am. Chem. Soc., 2014, 136, 10826; D. Balogh, Z. Zhang, A. Cecconello, J. Vávra, L. Severa, F. Teplý and I. Willner, Nano Lett., 2012, 12, 5835; L. Adriaenssens, L. Severa, D. Koval, I. Císařová, M. Martínez Belmonte, E. C. Escudero-Adán, P. Novotná, P. Sázelová, J. Vávra, R. Pohl, D. Šaman, M. Urbanová, V. Kašička and F. Teplý, Chem. Sci., 2011, 2, 2314; L. Severa, M. Ončák, D. Koval, R. Pohl, D. Šaman, I. Císařová, P. E. Reyes-Gutiérrez, P. Sázelová, V. Kašička, F. Teplý and P. Slavíček, Angew. Chem., Int. Ed., 2012, 51, 11972.

12 Introduction of helquat dyes: P. E. Reyes-Gutiérrez, M. Jirásek, L. Severa, P. Novotná, D. Koval, P. Sázelová, J. Vávra, A. Meyer, I. Císařová, D. Šaman, R. Pohl, P. Štěpánek, P. Slavíček, B. J. Coe, M. Hájek, V. Kašička, M. Urbanová and F. Teplý, Chem. Commun., 2015, 51, 1583.

13 L. D. Barron, L. Hecht, I. H. McColl and E. W. Blanch, Mol. Phys., 2004, 102, 731; L. Nafie, Vibrational optical activity: Principles and applications, Wiley, Chichester, 2011.

14 S. Abdali, J. Raman Spectrosc., 2006, 37, 1341; K. Osińska, M. Pecul and A. Kudelski, Chem. Phys. Lett., 2010, 496, 86.

15 S. Yamamoto and P. Bouř, Angew. Chem., Int. Ed., 2012, 51, 11058.

16 J. Šebestík and P. Bouř, Angew. Chem., Int. Ed., 2014, 53, 9236.

17 T. Wu, J. Kapitán, V. Mašek and P. Bouř, Angew. Chem., Int. Ed., 2015, 54, 14933.

18 L. A. Nafie, Chem. Phys., 1996, 205, 309.

19 G. Zajac, A. Kaczor, K. Chruszcz-Lipska, J. C. Dobrowolski and M. Baranska, J. Raman Spectrosc., 2014, 45, 859.

20 P. Bouř and T. A. Keiderling, J. Chem. Phys., 2002, 117, 4126.

21 P. Bouř, J. Sopková, L. Bednarová, P. Maloň and T. A. Keiderling, J. Comput. Chem., 1997, 18, 646.

22 S. Yamamoto and P. Bouŕ, J. Comput. Chem., 2013, 34, 2152. 